\title{
Procedural outcomes of a university nurse led vascular access unit in a Greek general oncology hospital
}

\author{
Katsoulas Theodoros ${ }^{1}$, Alexandrou Evan ${ }^{2}$, Konstantinou Evangellos ${ }^{1}$ \\ 1 National \& Kapodistrian University of Athens, Greece \\ 2 Liverpool Hospital, Western Sydney University, Australia
}

\section{Introduction}

Nurse led vascular access (VA) services have emerged based on the pressure to increase organizational efficiencies and patient outcomes. Most of the dedicated VA nurse teams are limited to peripherally inserted central catheter (PICC) procedures. However the existing literature although limited, suggests that insertion of centrally inserted central catheters (CICC) by specialist nurses may promote efficiency and minimize adverse events.

\section{Method}

This is a single center retrospective observational study from a nurse led VA unit of a 250 bed general-oncology hospital in Greece. The unit is operated exclusively by two university degree nurses who perform all the procedures under ultrasound guidance.

\section{Results}

A total of 1353 procedures were performed in a three years period (Fig 1).

- Five hundred fifty five CICCs were placed in medical and surgical ward patients $(95 \%$ IJVs) with a very low complication rate; $1.3 \%$ malposistion and $0.7 \%$ accidental artery puncture.

- A small number of 92 permanent dialysis catheters were placed in a dedicated suite $(77.2 \%$ IJV, $9.7 \%$ subclavian and $13 \%$ femoral veins).

- The other 706 procedures were 295 PICCs, 302 PICC ports and 109 chest ports placed in oncology patients of our hospital. Approximately $90 \%$ of Long term VA devices placement were uneventful.

The most common complication in PICCs was accidental removal of the catheter in $7.5 \%$ of the patients followed by $1.7 \%$ occlusion of the catheter, $1.4 \%$ catheter related bloodstream infection (CRBSI) and $1 \%$ catheter related thrombosis (CRT). Ports had a significant rate of dehiscence up to $5.1 \%$ followed by $2.2 \%$ CRT, $1.9 \%$ of pocket infection, $0.5 \%$ of CRBSI, $0.5 \%$ of catheter migration and $0.5 \%$ of catheter occlusion.(Table 1, Fig 2 \& 3)

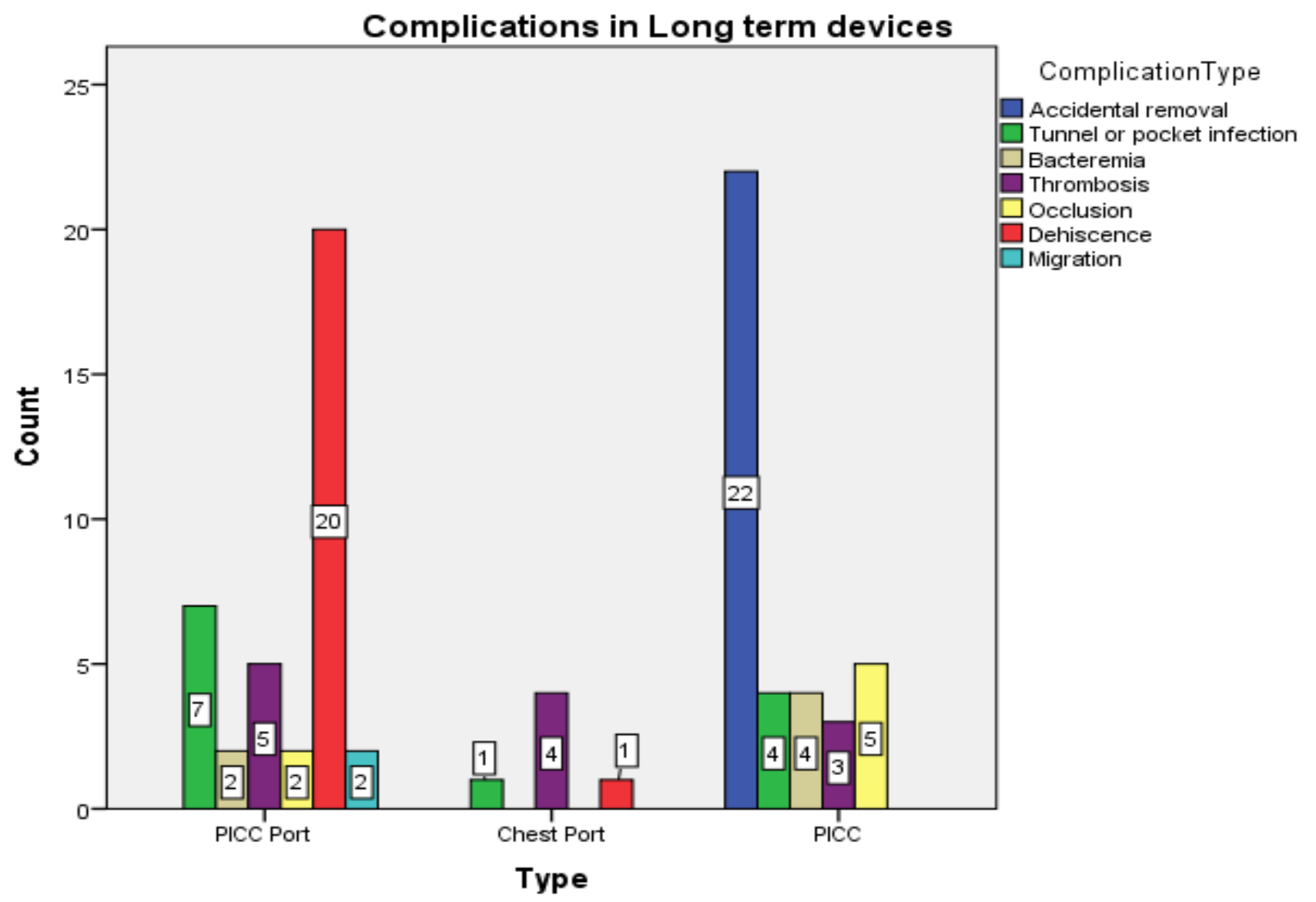

Figure 2: Complications in long term VA devices

References:

Alexandrou E, Spencer TR, Frost SA et al. Central venous catheter placement by advanced practice nurses demonstrates low procedural complication and infection rates - a report from 13 years of service. Crit Care Med. 2014;42(3):536-43.

2. Konstantinou EA, Karampinis DF, Mitsos AP et al. Central vascular catheters versus peripherally inserted central catheters in nurse anesthesia. A perspective within the Greek health system. J Vasc Access. 2013 Oct-Dec;14(4):373-8.

\author{
Procedures $(\mathrm{N}=1353)$ \\ CICCs $\square$ DCs $\square$ PICCs $\square$ PICC Ports Chest Ports
}

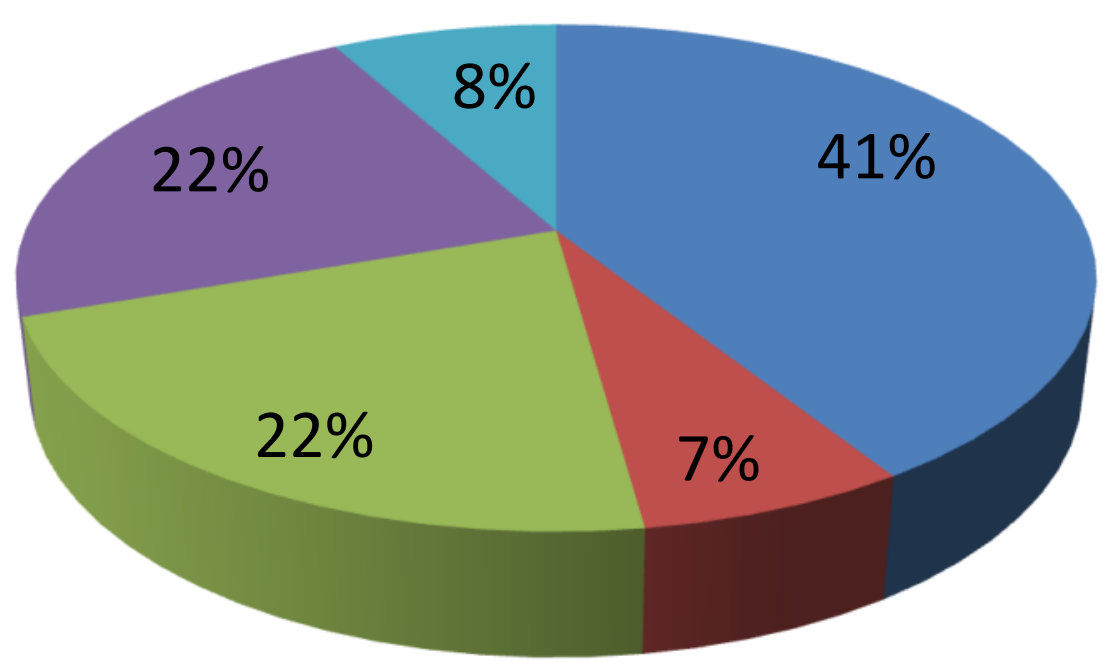

Figure 1: Procedures performed by the VA nurses

Table 1: Complications in long term VA devices

\begin{tabular}{|l|c|c|c|}
\hline \multicolumn{1}{|c|}{ Complications } & $\begin{array}{c}\text { PICC (N=295) } \\
(4 \mathrm{Fr})\end{array}$ & $\begin{array}{c}\text { PICC Port } \\
(\mathrm{N}=302) \\
(5-6 \mathrm{Fr})\end{array}$ & $\begin{array}{c}\text { Chest Port } \\
(\mathrm{N}=109) \\
(7-8 \mathrm{Fr})\end{array}$ \\
\hline $\begin{array}{l}\text { Accidental } \\
\text { removal }\end{array}$ & $22(7.45 \%)$ & $0(0 \%)$ & $0(0 \%)$ \\
\hline $\begin{array}{l}\text { Tunnel or pocket } \\
\text { infection }\end{array}$ & $4(1.35 \%)$ & $7(2.32 \%)$ & $1(0.9 \%)$ \\
\hline CRBSI* $^{*}$ & $4(1.35 \%)$ & $2(0.66 \%)$ & $0(0 \%)$ \\
\hline CRT $^{\star *}$ & $3(1.01 \%)$ & $5(1.65 \%)$ & $4(3.67 \%)$ \\
\hline Occlusion & $5(1.69 \%)$ & $2(0.66 \%)$ & $0(0 \%)$ \\
\hline Dehiscence & $0(0 \%)$ & $20(6.62 \%)$ & $1(0.9 \%)$ \\
\hline Migration & $0(0 \%)$ & $2(0.66 \%)$ & $0(0 \%)$ \\
\hline
\end{tabular}

${ }^{*}$ CRBSI: Catheter related blood stream infections

${ }^{*} \mathrm{CRT}$ : Catheter related thrombosis

\section{Discussion \& Conclusion}

This report describes the evolution of an advanced practice nursing role. High procedural success and considerably low complication rates are encouraging and suggest an important role of advanced nursing practice in improving patient health outcomes.

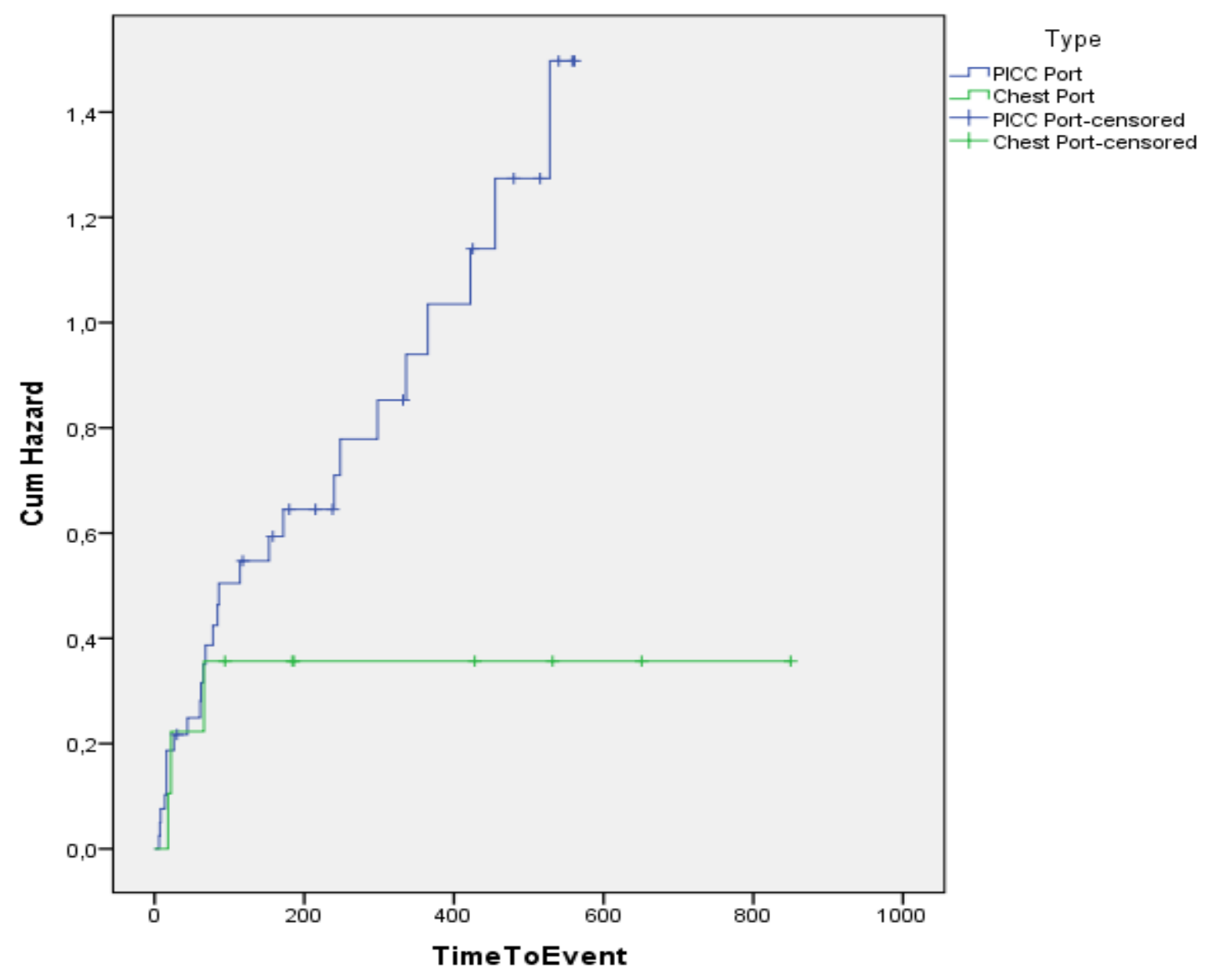

Figure 3: Complication Hazard of Chest Ports vs PICC Ports (Log Rank Mantel Cox 2.653, $\mathrm{p}=0.103$ ) 